\title{
Chapter 1 \\ Exploring the Interaction of Space and Networks in the Creation of Knowledge: An Introduction
}

\author{
Johannes Glückler, Emmanuel Lazega, and Ingmar Hammer
}

\section{A Conversation Between Spatial and Network Perspectives of Knowledge}

The book series on Knowledge and Space explores the nature of human knowledge from a geographical perspective. How to create, share, and adopt new knowledge is a core question in the social sciences. Processes of learning and knowledge creation are the result of social practice and always take place in space and in specific geographical contexts. The eleventh volume is the outcome of the symposium entitled "Topographies and Topologies of Knowledge" in the series of Klaus Tschira Symposia on Knowledge and Space held at the Villa Bosch Studio in Heidelberg. This book focuses on the conceptual and empirical intersections of the geographical and network dimensions of social practice in accounting for the creation and reproduction of knowledge. By taking up this dialogue between the fields of geography and social network studies, the book is conceived to bridge a research gap between two analytic perspectives that until recently have developed more in parallel to each other than in mutual exchange between scholars. The intention of its chapters is to broaden and deepen understanding of the specific characteristics not only of space and connectivity but also of their mutual and interactive effect on knowledge creation.

\footnotetext{
J. Glückler $(\bowtie) \bullet$ I. Hammer

Department of Geography, Heidelberg University,

Berliner Straße 48, D-69120 Heidelberg, Germany

e-mail: glueckler@uni-heidelberg.de; hammer@uni-heidelberg.de

E. Lazega

Department of Sociology, Institut d'Etudes Politiques de Paris (SPC) and,

Centre for the Sociology of Organizations (CNRS), 19, rue Amélie, 75011 Paris, France

e-mail: emmanuel.lazega@sciencespo.fr
} 


\section{Geography and Networks}

The network perspective has been influential in geography since the 1960s, when formal network analysis was used in what was called network geometry. By adopting the concept of topology from mathematics (Matthes, 1912), geographers integrated topographic and topological perspectives into the analysis of spatial networks. With this new method, geographers sought to solve puzzles such as the traveling salesman ${ }^{1}$ to determine optimal routes involving the shortest paths in transport and utility networks (Greenberg, Carey, Zobler, \& Hordon, 1971; Sagers \& Green, 1982). Haggett and Chorley (1969) developed a comprehensive approach for the optimization of network geometry, which they considered to be the most interesting research topic of location theory at the time. This research has become an important topic especially in engineering disciplines such as operations research, computation science, mathematics, and economics. Journals such as Networks and Spatial Economics and Operations Research focus on models, techniques, algorithms, and research questions and on ways that production networks, supply chain management networks, infrastructure, and communication networks can be organized and optimized.

Since the 1980s, the research interest in geography has increasingly shifted from material to social connections and from a quantitative to a rather qualitative approach to capturing the multidimensional processes developing in local and global environments. Unlike physical infrastructure, social relationships do not necessarily follow a linear logic by which costs rise or connectivity weakens as distance increases. Geometric distance cannot be accepted as a sufficient condition for determining social interactions. Instead, the availability and use of communication and transport technologies mediate the relationship between physical proximity and social interaction. The relation between space and social interaction depends on the actor's choice of technology and mobility (Glückler, 2007). Today, geography is interested in the quality rather than the physical metrics of social and organizational relations.

Knowledge is a key resource in economic development, prosperity, and wealth (e.g., Jacobs, 1969; Romer, 1990; Schumpeter, 1911). Knowledge is also socially constructed and diffused in the relational network among people (Brown \& Duguid, 1991; Knorr-Cetina, 1981; Wenger, 1998). Geographers have therefore focused on the question to what extent geography influences learning, knowledge creation, and innovation by rejecting the traditional models that calculate the probability of a tie as a function of metric distance (Bathelt \& Glückler, 2011; Maskell, 2001; Maskell \& Malmberg, 1999). A fundamental observation in the geography of knowledge is that knowledge is often sticky with regard to place and difficult to transfer to or reproduce in other places (Bathelt \& Glückler, 2011; Gertler, 1995; Storper, 1997; von Hippel, 1994). This stickiness sometimes leads to idiosyncratic

\footnotetext{
${ }^{1}$ The problem of the traveling salesman consists in finding the minimal route for a journey that starts and ends at the same location and has to pass through a determinate number of intermediary destinations.
} 
knowledge specific to certain places and poses challenges to learning and imitation over distance (Malmberg \& Maskell, 2002). From an economic perspective, such epistemic idiosyncrasies may be sources of competitive advantage in some regions where they foster innovative practice, learning, and economic development, while other regions lag behind and face the challenge of catching up.

Researchers interested in geography's particular role in knowledge creation have studied innovative regions with technological and knowledge clusters such as Silicon Valley (Klepper, 2010; Saxenian, 1994), Boston (Bathelt, 2001; Glaeser, 2005; Tödtling, 1994), Bangalore (Lorenzen \& Mudambi, 2013), and London (Cook, Pandit, Beaverstock, Taylor, \& Pain, 2007; Keeble \& Nachum, 2002) to find out how physical proximity and face-to-face contact help create and circulate new ideas and knowledge. Geographical proximity allows for planned as well as serendipitous encounter and interaction, and it allows for learning even in the absence of immediate social relations simply by virtue of one's "being there" (Gertler, 1995, p. 1) and observing others in proximity (Malmberg \& Maskell, 2002). In this context, Abbott (2001) cited French sociologist Émile Durkheim (1897/1951, p. 123):

A cough, a dance-motion, a homicidal impulse may be transferred from one person to another even though there is only chance and temporary contact between them. They need have no intellectual or moral community between them nor exchange services, nor even speak the same language, nor are they more related after the transfer than before (p. 141).

In summary, the discipline of geography has developed a deep and diversified understanding of learning, knowledge creation, and innovation in and between places and spaces. Geographical places may become specific milieus (Camagni, 1991; Meusburger, 2009) where people enjoy access to localized knowledge and where they learn from others to come up with new ideas and innovations themselves. But the social and more formal understanding of relational processes has been neglected until recently.

\section{Social Processes, Social Networks, and Distance}

In the social sciences the shoe is on the other foot. Whereas thinking of places and spaces has been a matter of physical distance, formal network theory has deepened human understanding of learning and knowledge creation as a social process. In general, social network researchers are interested in the nature, antecedents, and outcomes of social connectivity. Formal network analysis and the conceptual emergence of relational thinking in the social sciences (see Marsden \& Lin, 1982, and Wellman \& Berkowitz, 1988, for instance) have led to new research designs and have yielded ground-breaking empirical discoveries that challenge established categorical reasoning. New theoretical perspectives, methodologies, and concepts have been developing within the framework of relational thought (Doreian, Batagelj, \& Ferligoj, 2005; Kilduff \& Tsai, 2003; Snijders \& Steglich, in press-a; Wasserman $\&$ Faust, 1994). Some scholars push this relational thinking as far as arguing that the basic assumption of a relational social science is the "anticategorical imperative" 
(Emirbayer \& Goodwin, 1994, p. 1414). It stipulates understanding social phenomena such as identity, power, conflict, social capital, and knowledge as expressions and consequences of the positions and associations that actors enjoy or endure within systems of social interdependencies and relations rather than as substantialist, monadic entities with predetermined characteristics (Bathelt \& Glückler, 2005). In a relational perspective the focus is on individual and collective opportunities for action, and these opportunities are thought of as being facilitated by the specific context and structure of social relations.

Beyond early radical relational sociologies, current theories move on, prodded by the founding fathers of contemporary structuralism (e.g., White, 2008) to combine relational and categorical approaches as well as relational and cultural perspectives that bring classical social science theory and network analyses into a neostructural framework (e.g., Brandes, 2016; Breiger, 1974, 1990, 2010; Snijders, 2005; Snijders \& Steglich, in press-b). From these perspectives a relational topology is also a social space in which specific social processes driven by these relationships take place in a meaningful way for the actors themselves (Lazega \& Pattison, 2001). Generic social processes examined by the social sciences since their emergence (e.g., solidarity and discrimination, collective learning and socialization, social control and conflict resolution, and regulation and institutionalization) are partly the product of the regularities constructed in the management of interdependencies between actors in conflict and/or in cooperation. These processes facilitate the management of collective action's dilemmas at each level of agency. The role of network analysis evolves toward modeling these processes and helping with theorizing them.

Building knowledge in individual and collective learning is precisely one such generic process. Such a theoretical perspective necessarily implies an analytical focus on connectivity in social and economic action. Those new theories and concepts have been the key ground-breaking insights into models and concepts of knowledge creation and knowledge diffusion. How does knowledge about this generic process benefit from this approach? Network analyses from several angles are useful for answering this question. Learning, knowledge creation, and innovation are all fruit of the circulation and interpretation of information, the co-creation of new ideas, cumulative experience, and cognition. People relate to other people inside and outside organizations in order to exchange information, knowledge, goods, services, and capital. The myriad individual and collective actors and the relations they sustain are the building blocks of social networks. Relationships are important for the acquisition of information (Borgatti \& Cross, 2003), and the creation of knowledge has been recognized as a social, interactive process (Lawson \& Lorenz, 1999). Networks are not merely a representational form of social relations but also a social context. A network is "a specific set of linkages among a defined set of persons, with the additional property that the characteristics of these linkages as a whole may be used to interpret the social behavior of the persons involved" (Mitchell, 1969, p. 2). This definition implies that the specific structure of relations may be used to draw inferences and expectations pertaining to individual and col- 
lective action (Gulati, 1995; Mizruchi, 1994). Networks affect opportunities for action (Burt, 1992).

Therefore, the capacity to learn collectively depends on specific relational infrastructures (Lazega, 2016; Lazega, Bar-Hen, Barbillon, \& Donnet, 2016) that are available for such a social process. One exemplary source of knowledge and learning is advice-seeking. Advice does more than transmit information that will be used to build knowledge. What is being pragmatically transmitted in an advice relationship is also a framework for the evaluation and interpretation of this information, the elements necessary for the evaluation of its appropriateness as a basis for knowledge-building. This point is where relational infrastructures such as social status and social niches come in. For example, recognition of status gratifies the advisers by providing them with an incentive to share their knowledge and their experience (Blau, 1964).

Advice networks are highly interdependent with collaboration, friendship, and other types of social networks that help mitigate the status rule (Lazega \& Pattison, 1999): Both collaboration and friendship can lead to advice and vice-versa. This multiplexity indicates the presence of reference groups or epistemic communities. A longitudinal analysis of advice networks adds to the picture by showing that, in many organizations examined by researchers, advice-seeking converges toward senior members recognized for having the "authority to know". They provide social approval for specific decisions and contribute to the integration of the organization because they link the individual, group, and organizational levels. This alignment is a key ingredient of intraorganizational collective learning. In addition, the dynamics of advice networks are cyclical: A pattern of centralization-decentralizationrecentralization is generated by epistemic leaders seeking a balance between overload and conflict (Lazega et al., 2016). The described mechanism suggests that epistemic leaders who drive collective knowledge-building through alignments are precisely those who can remain at the top of the epistemic pecking order throughout the cyclical process.

Social network studies also point to a number of structural conditions that are conducive to innovation, such as the number of relationships (e.g., Powell, Koput, \& Smith-Doerr, 1996; Zaheer, Gözübüyük, \& Milanov, 2010), the quality of those relationships (Granovetter, 1985; Uzzi \& Lancaster, 2003), and the location of an actor in the overall structure of a network (Whittington, Owen-Smith, \& Powell, 2009). Researchers have found various structural concepts to be positively related with innovation, such as actor centrality (Owen-Smith \& Powell, 2004; Whittington et al., 2009), boundary-spanning locations between one's own group and other groups (Krackhardt \& Stern, 1988), and intermediate positions between a core and a periphery (Cattani \& Ferriani, 2008). Theories of structural holes (Burt, 1992, 2004; Obstfeld, 2005) and of structural folds (Vedres \& Stark, 2010) have developed rich explanations of how network location affects the access to information and the co-creation of knowledge. The existence and the quality of relations as well as specific structural characteristics of locations have been theorized as helping or hindering social outcomes such as economic performance or innovativeness. The geography of learning, knowledge, and innovation as a social process between peo- 
ple of different places and spaces has become an important research issue in social network analysis. But despite the growing literature in that field, one of the main criticisms concerning relational thinking is the reductionist, geometric focus on distance. Geography is often treated only as a cost function of linear distance rather than as a matter of multifaceted and rich social context (Daraganova et al., 2012; Doreian \& Conti, 2012).

\section{Beyond Disciplinary Silos: The Uncharted Interrelation of Learning, Knowledge, Relations, and Space}

Despite the potential of combining the relational and the geographical perspectives, there has long been unintended silence between the two fields in knowledge studies. Geography has endorsed the term network as a rich metaphor of social cohesion and cooperation rather than of formal structure (Grabher, 2006); network research has often ignored the spatial dimension of social networks and used regions merely as a convenient shell for the empirical analysis of interpersonal and interorganizational relations. Recently, however, scholars from various fields in the social sciences have realized that both dimensions - geography and relational thinking — are important for knowledge creation and learning (e.g., Doreian \& Conti, 2012; Glückler, 2013). Gatherings such as the Capturing Context Conference (Columbia University, June 2009) and the International Workshop on Social Space and Geographic Space (University of Melbourne, September 2007) and a special issue of Social Networks in 2012 have brought together researchers interested in discussing new research questions and solutions at the intersection of the two fields (Adams, Faust, \& Lovasi, 2012). Overall, the interdisciplinary study of knowledge creation and innovation at the junction of space and social networks has only emerged in recent years. A closer look at the recent literature that has included both spatial and network dimensions in the study of innovation suggests that networks, geography, and knowledge are conditionally related to each other. At least four linkages within this conceptual triangle have been studied empirically: (a) geography as a condition of network formation, (b) geography as a moderator of the effects of network on knowledge, (c) networks as a moderator and (d) networks as a mediator ${ }^{2}$ of the effects that geography has on knowledge. With the "agentic turn" (Kilduff \& Brass, 2010, p. 336) and an expanding perspective on multilevel networks, a fifth linkage emerges, (e) agency as a moderator of "places" in multilevel relationships on collective learning. We briefly summarize some of the insights of these studies in order to identify the uncharted interrelation of knowledge, networks, and space. ${ }^{3}$

\footnotetext{
${ }^{2}$ A moderator variable governs (e.g., increases or decreases) the strength of a relationship between two other variables, whereas a mediator variable explains the relationship between two other variables (Baron \& Kenny, 1986).

${ }^{3}$ The following discussion on the interrelation of geography and network studies is based on Glückler (2013).
} 


\section{Space as a Condition for Network Formation}

One dominant line of research has focused on the geographical constraints on the very process of network formation ${ }^{4}$ and its evolution. This approach is based on findings that geographical proximity tends to facilitate network formation; it increases the likelihood for social encounter, the exchange of information, and the creation of social relations (Allen, 1977; Zipf, 1949). Empirical research on network evolution confirms the plausible expectation that new relations are more likely to emerge in geographical proximity than over large distance (Broekel \& Boschma, 2012; Glückler, 2010; Powell, White, Koput, \& Owen-Smith, 2005). Recent research in evolutionary economic geography has underscored the association between geographical proximity and tie formation in networks by empirically controlling for other forms of proximity (Balland, 2012). These and other accounts of geographical constraints of network formation and evolution form part of what Borgatti and Halgin (2011) would classify as geographical theories of networks. Consequently, networks are located in space, and the creation of new linkages seems to be somewhat affected by this geography. Conversely, the creation of new ties in a network is an important strategy for bridging physical separation and enable communication and exchange over large distance (Glückler, 2005). The mutual conditionality between space and networks is thus a fascinating and still unexplored area of research. More complicated, however, is the question of how space and networks interact in their combined effect on the creation and reproduction of knowledge.

\section{Space as a Moderator of Network Effects on Knowledge}

The first interactive linkage between space and networks points to the moderating effect of space on the impact of network on innovation. In an interesting research design, Owen-Smith and Powell (2004) analyzed Boston-based biotech firms and their global alliance network. They found that although actor centrality was an important factor of innovativeness in the global network, it was insignificant within the regional network. Defying the intuition of network theorists, firms were equally likely to innovate independent of their position's centrality in the network as long as they were connected to the local alliance network. Geographical proximity thus moderated the effect of network centrality on innovation. One explanation of this finding is that proximity allows for knowledge spillovers within the entire network of alliances and beyond the dyadic alliances. In a subsequent analysis of U.S. biotechnology, Whittington et al. (2009) demonstrated that the innovativeness of biotech firms benefits from geographical proximity and network centrality in ways that

\footnotetext{
${ }^{4}$ See Adams et al. (2012), in particular Butts, Acton, Hipp, and Nagle (2012); Daraganova et al. (2012); Doreian and Conti (2012); Lomi and Pallotti (2012); Viry (2012); Preciado, Snijders, Burk, Stattin, and Kerr (2012); Sailer and McCulloh (2012); Takhteyev, Gruzd, and Wellman (2012); Verdery, Entwisle, Faust, and Rindfuss (2012).
} 
depend on a variety of factors. The effect of the centrality of firms in the interorganizational network was very much a function of proximity: Highly central firms were more likely to be innovative if sited close to other firms than if sited far away from them. This finding corresponds with those reported in more recent studies in the context of trade fairs (e.g., Brailly, Favre, Chatellet, \& Lazega, 2016a; Favre, Brailly, Chatellet, \& Lazega, 2016; Piña-Stranger \& Lazega, 2010).

\section{Connectivity as a Moderator of Spatial Effects on Knowledge}

The same kind of effect seems to be at work in the opposite case. It is usually accepted that information transfer and knowledge spillovers dwindle with geographical distance. In the context of international technology transfer between units of multinational corporations, Hansen and Løvås (2004) explicitly focused on interaction effects between the major factors of technology transfer. Their analysis conveyed that the relations between distributed organizational units clearly moderate the association between technology transfer and geography. Units were found more likely to transfer technology successfully over large distances if they were connected through interpersonal ties or through formal organizational linkages than if there were no such links. Bell and Zaheer (2007) suggested that the kind of relationship, whether at the individual, organizational, or institutional level, varies in its dependence on geographical proximity. Empirically, they reported rather counterintuitive evidence for what they call geographic holes, that is, situations where information flow is facilitated between friends when they are geographically distant. In a similar vein, research on contractual alliances (Rosenkopf \& Almeida, 2003) and informal business relationships alike (Glückler, 2006) illustrates how relationships substitute for local search and how they help bridge distance. Lastly, learning-byhiring can be useful for extending the hiring firm's geographic reach and access to remote knowledge (Song, Almeida, \& Wu, 2003). In all these research designs, the existence and characteristics of networks affect the strength of the association between geography and knowledge.

\section{Connectivity as a Mediator of Geographical Effects on Knowledge}

A fourth stream of innovation research suggests that networks mediate the entire effect of geography on innovation. Empirically, patents are cited more frequently within the region in which they were invented than in others (Jaffe, Trajtenberg, \& Henderson, 1993; Thompson \& Fox-Kean, 2005). This finding supported the argument that trajectories of technological knowledge are spatially sticky. However, new research designs were needed to examine how these local spillovers happened. Almeida and Kogut (1999) found that local spillovers did not occur equally across 
regions and that those regions with the strongest spillovers in technological development were the ones where job mobility was restricted mostly to intraregional job moves. Using network analysis, even more sophisticated research designs have illustrated that patent citations tend to be local because inventors tend to change jobs locally and stay within their labor-market region (Breschi \& Lissoni, 2009). This evidence suggests that the most fundamental reason why geography matters for localized knowledge creation is the relative immobility of researchers. The job mobility of inventors increases the transfer of technological knowledge (measured as patent citations) between firms independently of geography (Rosenkopf \& Almeida, 2003). In support of this conclusion, Breschi, Lenzi, Lissoni, and Vezzulli (2010) offered evidence that proximate and remote job moves occur in equal proportions, and Song et al. (2003) demonstrated that both proximate and distant hiring of inventors lead to effective transfer in technological knowledge as measured by patent citations. A second example of how networks mediate the relation between space and knowledge is provided in the context of information search. Borgatti and Cross (2003) found that when one knows an informant and can access that source, physical proximity is no longer associated with information transfer. ${ }^{5}$ In summary, this line of research suggests that the association between geography and knowledge is not a direct effect, that it is mediated through inventor mobility, the accessibility of other partners, and prior knowing.

\section{Agency as a Moderator of Relational "Places" in Multilevel Relationships on Collective Learning}

Social scientists, especially sociologists and geographers, have arguably been building a strong alliance in the social sciences to measure, model, and understand the multilevel dynamics of places, positions, and the effects of such dynamics on all the generic social processes we are interested in, notably knowledge-building and collective learning. In particular, when complex position in an organized system of places allows actors to try and change that formal structure (albeit with varying success), scholars interested in spatial and organizational movement can help combine institutional locations, position in relational infrastructures (e.g., status and niches), and geographical place (e.g., Bathelt \& Glückler, 2011; Glückler \& Hammer, 2012).

Social processes such as collective learning and knowledge creation are also contingent on multilevel interdependencies and require unprecedented amounts of coordination among actors at and across given levels. Actors think in multilevel terms ("this person is a big fish in a big pond") and are required to manage these

\footnotetext{
${ }^{5}$ Mediation implies that the mediated variable (proximity) predicts the mediating variables as well as the dependent variable (e.g., innovation, information exchange) and that the coefficient for the mediated variable becomes insignificant when the mediators are included in the model (Baron \& Kenny, 1986).
} 
exceptionally complex interdependencies (e.g., functional, epistemic, normative, emotional) in sophisticated ways at different levels simultaneously. Actors thus face multiple dilemmas of collective action. Without this multilevel coordination between individuals, between organizations, and between individuals and organizations, neither individuals nor organizations can access or mobilize on their own all the resources that are needed to produce, compete, and survive.

Collective learning and knowledge-building are heavily dependent on the existence of such superimposed levels of agency, each of them characterized by horizontal interdependencies that sociologists can examine as sets of local social systems. Interpersonal interdependencies consist of individuals tied together within or across organizations through cowork, advice, friendship, and the rules that organize their social exchanges. The content of these relationships varies. This level of agency is different from that of the organizations to which these same individuals are affiliated. Interorganizational interdependencies are created most often by contractual agreements between organizations specifying the contributions, rights, and responsibilities of each organization in the pursuit of a particular objective, but they also depend on the existence of institutions that guarantee the credibility of those contractual agreements. Economic, contracting activity has been shown, for instance, to depend heavily on collective learning and knowledge-building at the interpersonal level (Brailly et al., 2016a, 2016b). Cross-level interactions between individuals and organizations as well as reliance on collective learning built into such cross-level interactions are vital in the organizational society. In a multilevel context where each level has its own temporality, synchronization costs are effortsmade by individuals and by organizations in very asymmetrical ways - to keep pace with each other by reshaping a structure of opportunity and constraints. Given this complexity, geography's focus on the spatiality of knowledge creation is crucial to social sciences that need the dynamics of multilevel structures to understand current organizational societies.

\section{Enhancing the Conversation}

This book intends to open the floor for engaged conversation between topographies and topologies of knowledge. As the brief appraisal of these different lines of research suggests, the empirical evidence of the association between geography, networks, and knowledge is still inconclusive. To some scholars, geography appears to be a force; to others, a moderator. To still others it is only an indirect factor mediated by more important factors such as connectivity. These empirical contingencies may be consequences of the variety and incomparability of methodologies and measures as well as of the kinds of knowledge and networks observed. Whereas geography is often observed either as a binary (inside/outside a region) or as a measure of geometric distance, network relations and the types of knowledge and relations vary widely. Relations in networks range from informal to contractual relationships and from individual to organizational levels. New knowledge is usually measured as 
successful patent applications, although innovation occurs in many other forms, too. These different semantics and metrics are likely to produce different effects and may cause much of the observed contingencies. What this nascent research indicates is that both networks and geography play elementary roles in understanding the creation, use, and reproduction of knowledge. Yet researchers are only at the beginning of a more comprehensive understanding of the way in which the two modes of being there and being connected are interrelated in the social creation of new ideas and innovations.

We contend that the complex interrelations between networks, space, and knowledge can be solved only if approaches from different disciplines are combined in a multidisciplinary way. Their individual contributions help integrate both network arguments of connectivity and geographical arguments of contiguity and contextuality into a more comprehensive understanding of the ways in which people and organizations are constrained by and make use of space and networks for learning and innovation. Examples are the cases that call for recognition that social and collective learning is moderated by economic networks, intercultural relations, or relational turnover. Another example is when the contributors to this book extend the current research frontier by solving the puzzle of how learning in the past shapes knowledge creation in the future, or how positions of institutions and people shape the geography of learning and knowledge creation. Coming from the fields of geography, sociology, economics, political science, psychology, management, and organizational studies, the authors of the chapters in this volume develop conceptual models and propose empirical research that illustrate the ways in which networks and geography play together in processes of innovation, learning, leadership, and power.

\section{Structure of the Book}

The research questions raised in the following fifteen chapters stem from three main perspectives. The first addresses the significance of knowledge about networks and the insight that relational thinking serves as a principle bridging between economic, social, and geographic issues. Networks are moderator, mediator, and input factors for learning, knowledge, and innovation in and between places and space. The contributors to this part of the volume consider relations between the social and the economic dimensions and trace social networks of knowledge through the spheres of business, education, polity, and family, expanding knowledge about the meaning and role that relational aspects have in both the social and economic dimensions.

Networks are embedded systems of multiple social or economic relationships developed through the agency of different actors. These systems encompass different relational places, so social relations and their effect on learning and innovation are constantly in flux. The second perspective picks up on that stream of research by presenting an evolutionary viewpoint on networks and space. The authors add to the discussion about models of relational systems by conceptualizing and exploring 
them; explaining and investigating mechanisms, structures, and the development of tie formation and agency; and identifying the benefit of relational systems for regions. This section shows knowledge about the evolution of relational structure to be a key determinant of social and regional development.

The third perspective presented in this volume integrates geography, connectivity and knowledge creation. The authors adopting it take space, networks, and actors to be origins of new knowledge and innovation. Those rather economic models not only help improve individual, regional, and organizational innovation but also show how the desired outcome is achievable. In short, the contributors to this volume bring together new research questions, concepts, and empirical work from economics, geography, sociology, and management science to offer new insights by combining the relational view of networks with the geographical view of locations and space with respect to knowledge and learning.

\section{Knowledge About Networks}

Part I, consisting of five contributions, points to the importance of knowledge about networks. This section of the volume highlights from a theoretical point of view the relational dimension as a multilevel problem mutually influenced by social, economic, individual, and geographical issues. The authors, with their research agendas, carve out how new perspectives on those manifold relationships broaden human knowledge about relational issues surrounding the intersection of knowledge, space, and agency. In the opening chapter, "Reversing the Instrumentality of the Social for the Economic: A Critical Agenda for twenty-first-century Knowledge Networks," Nancy Ettlinger reverses the direction of causality between the economic and the social dimensions of knowledge networks and questions the classical argument that social aspects serve economic outcomes. She develops a critical agenda for two purposes. First, she uses theories about knowledge generation, the generation of economic knowledge, and networks to develop social knowledge by dissolving frictions caused by difference and constructing an inclusive system of collaborative work. Second, she uses the market itself to adapt new corporate strategies to social ends in the course of sustaining, if not augmenting, productivity.

The chapter thereafter elaborates on the growing importance of intercultural competence and learning in a world of rapid internationalization and globalization. The text outlines a possible solution to the following problem: When employees of small- and medium-sized enterprises and large corporations are sent on foreign assignments, the ensuing clash of cultures could lead to emotional or psychological withdrawal although the business opportunity calls for social closure. Setting out from the individual's point of view, the author, Erika Spieß, elaborates a model that takes various influential factors into account, such as the social network of expats, cultural processes, and the current economic and political environment. In a broader interpretation, this chapter can be seen as an initial empirical perspective on and solution to the agenda that Ettlinger discusses. By developing models that offer an 
insight into how intercultural learning processes take place, researchers learn how economic factors influence the social dimension when the learning process is triggered by economic requirements, namely, the pursuit of international business.

The fourth chapter, by Pengfei $\mathrm{Li}$, takes a more conventional perspective by investigating how social aspects influence the economic dimension. He examines the role of family and friendship networks as bridges for technology diffusion in developing countries. When regional economies take off, the role of family networks in localized learning weakens. By contrast, another kind of social network, friendship ties, are more open and dynamic in fostering regional innovation in the knowledge economy. The transformation from family- to friend-based learning is not easy. Many developing economies become stuck in a transition stage that arises after the collapse of traditional social connections and before the establishment of generalized trust and formal institutions has created spontaneous associations of individuals. Concentrating on the interdependencies between different forms of social relationships, Pengfei Li conceptualizes how this transition could take place.

In the fifth chapter Laurent Beauguitte considers the "national-local" aspect as a moderator of global networks. He unravels the increasing interaction of local, global, economic, and social issues by investigating processes of political regionalization on a world scale. Starting from the assumption that political actors are called upon to work more and more often on a supranational basis, he proposes that this arrangement is not only a response to global economic processes but also a reaction to the rise of global issues demanding a change in governance. He analyzes the United Nations General Assembly (UNGA) from 1985 to 2010. With nearly all states being represented in this organization, it allows him to observe patterns of cooperation on a world scale from both dynamic and thematic points of view. A variation of the search for equivalence allows him to map the geographical clusters revealed by voting positions. In a second analysis he examines patterns of speeches and reveals the rising importance of regional groups at the UNGA. Lastly, Beauguitte proposes a theoretical model of cooperation among actors at the UNGA.

In the final chapter of Part I, Sarah Hall discusses networks as a moderator of individual learning by examining new strategies in undergraduate and graduate education markets. Her treatment builds on the investigation that this section's other authors conduct into the interrelationship between social and economic issues. She finds that policy-makers and employers in advanced economies have increasingly framed both kinds of market as an important way to improve graduate employability and enhance economic growth within "knowledge-based economies." However, graduates seeking to enter those elite labor markets have faced increased competition in recent years, driven, for instance, by the financial crises after 2007. Sarah Hall analyzes an emerging strategy that has received less attention than others: the growing use of postgraduate educational services and training. She argues that attaining additional credentials is an important strategy among graduates seeking entry into elite global labor markets and, consequently, for the production, reproduction, and circulation of geographically variegated economic elite knowledge practices. 


\section{Network Evolution and Social Outcomes}

Part II of the book addresses the matter of network evolution and its impact on individuals and regions. Emmanuel Lazega offers a neostructural perspective on how organized mobility and relational turnover (OMRT) constitute important dimensions of the social context in which social mechanisms are deployed. He investigates how rotation across a carrousel of organizational places and subsequent relational turnover create a relational infrastructure that shapes the social process of collective learning. An advice network among lay judges serves as an empirical context in which to develop a "spinning-top model" of collective learning. It accounts for the dynamics of these networks, in particular their cyclical centralization and decentralization over time, with OMRT in the organization providing the energy that drives this evolution. Emmanuel Lazega identifies stability from movement at the heart of collective learning and from its multilevel character and consequences.

Charles Kirschbaum investigates how the relational environment mediates individual possibilities. He studies a 40-year evolution in jazz to analyze how that relational field affects the trajectories of individual musicians. By using relational data on the credits of 5571 albums to extract social-network statistics, he builds idealtypical trajectories of musicians' paths. Additionally, Kirschbaum uses methods of block-modeling to map the field's development in light of the positioning of trajectory types and the evolution of styles. He demonstrates how the field of jazz moved from a normative to a more competitive structure as older generations were coopted by new ones.

The ninth chapter advances knowledge about the topology and evolution of collaboration networks in a policy-anchored, high-tech district in Italy. Laura Prota, Maria Prosperina Vitale, and Maria Rosaria D'Esposito use prespecified blockmodeling to identify the structural configuration of collaboration over time, tracing the evolutionary path of collaboration within the district. Providing an assessment of the district management strategy, their empirical results show that initial collaboration assumed a core-periphery configuration characterized by a single, small bridging core of research organizations. Gradually, this configuration changed, developing a large cohesive nucleus connected to global partners through generalized bridging ties.

Jörg Sydow and Friedemann Koll investigate the possibility of designing regional technological capabilities by injecting related variety into regional development processes not only in terms of knowledge resources but also of agents, activities, and relations - a problem they conceptualize as "platforming." Using a case-study approach to the electromobility initiative in Germany, the authors investigate the potential of platforming for unlocking such path dependencies. The empirical results lead them to conclude that platforming may contribute to path-forming, but not necessarily to path-breaking, at a regional level.

The final chapter in this section takes up the question of tie formation and governance from the perspective of agency. Studying a high-tech firm employing 116 professionals, authors Martin Kilduff, Ajay Mehra, Dennis Gioia, and Stephen 
Borgatti develop a fine-grained picture of the emergence of informal leadership. They find that high self-monitoring emergent leaders notice problems and ameliorate them by providing advice and brokering relationships across social divides. Occupying a structurally advantageous position may well be more advantageous for some individuals (i.e., high self-monitors) than for others (i.e., low self-monitors). This study adds to the understanding of the contingency related to the social outcomes of a particular structural position.

\section{Network Geographies of Learning}

Part III of this book focuses on the different forms of network outcomes, especially learning, knowledge, and innovation. The researchers in this section deepen the knowledge about how networks moderate, mediate, and contribute to individual and collective learning and about how history as well as social and geographical factors influence those outcomes. Satyam Mukherjee, Brian Uzzi, Ben Jones, and Michael Stringer investigate in chapter twelve how novelty builds on conventional and atypical knowledge alike. Their analysis of 17.9 million papers spanning all scientific fields suggests that science follows a nearly universal pattern, with the highestimpact science being grounded primarily in exceptionally conventional combinations of prior work yet simultaneously featuring an intrusion of unusual combinations. Novel combinations of prior work are rare, yet teams are more likely than solo authors to insert novel combinations into familiar knowledge domains.

In the chapter thereafter, Johannes Glückler and Ingmar Hammer theorize the interactive effect of connectivity and spatial proximity on mechanisms of learning. They argue that connectivity among firms facilitates purposive collaboration and forms of friendly imitation, whereas spatial proximity also enhances the mutual visibility among even disconnected firms, raising the incentives for unfriendly forms of rival learning and unilateral imitation. Drawing on the case of an organized business network of independent IT firms in eastern Germany, the analysis demonstrates that the co-occurrence of connectivity and colocation facilitates both friendly and unfriendly practices of imitation. The social tensions that emerge from unfriendly imitation are mitigated by social conventions and sanctions and thus promote realization of individual and long-term collective opportunities.

Since the path-breaking work by social scientists and statistical methodologists, the sense of the importance that agency, roles and positions have for knowledge creation has sharpened. "Are gatekeepers important for the renewal of the local knowledge base? Evidence from U.S. cities" broaden knowledge about roles, positions, and knowledge creation within a geographical framework. In chapter fourteen, Stefano Breschi and Camilla Lenzi offer an exploratory perspective on the importance of gatekeepers for the expansion and renewal of the knowledge base of U.S. cities. The authors propose and test a number of indicators accounting for what the gatekeeper does to mediate knowledge flows across cities. Their findings indicate that external direct relations are the key mechanism injecting fresh knowledge 
into a city and amplifying opportunities for technological recombination. Conversely, the greater the reliance on external relations governed by gatekeepers, the less the impact on the expansion and renewal of a city's knowledge base. Distributed, networked learning processes are widely touted as a basis for superior performance.

Recognizing a lack of knowledge about how learning networks operate in the aggregate, Christopher Ansell, Martin Lundin, and Per Ola Öberg seek to widen the view on networks and learning. They take an explicitly geographical perspective into account by utilizing a unique dataset on learning among Swedish municipalities. The authors find that municipalities learn from their near neighbors, especially those in the same county. This research also provides evidence that Swedish municipalities are a "small world" linked together at the national level. Two mechanisms knit the Swedish municipalities together. First, county seats serve as "hubs" that bind local clusters. Second, local clusters aggregate into regional clusters. Despite a high degree of local clustering, hubs and regions provide a structural basis for the national diffusion of policy ideas and practices among Swedish municipalities.

In the final chapter of the book, Uwe Cantner, Susanne Hinzmann, and Tina Wolf take a dynamic approach to investigating the coevolution of cooperation ties and various dimensions of proximity between potential collaboration partners. Specifically, they highlight the predominant role of cognitive proximity for the continuity of innovation-oriented alliances and take into account that this proximity changes over time. They find partner-switching more often than the repetition of collaboration. Neither knowledge transfer nor mutual experience with cooperation shows significant effects on repeated cooperation. Instead, the authors find cooperation to be favored by similarity (overlap) between the firms' knowledge bases, an imbalance in the reciprocal potential for knowledge exchange, the general experience the partners have with collaboration, and similarity in the degree of popularity of collaboration partners.

\section{Conclusion}

With this book we continue the interdisciplinary discussion on relational, geographical, and knowledge perspectives. Researchers from different disciplines have long developed important insights from their very different perspectives, and every perspective has its own strengths and weaknesses. In drawing on the strengths of each discipline and its specific point of view, the understanding of the interdependencies between networks, learning, and space becomes increasingly comprehensive. Collectively, the chapters in this volume are but a small step in this endeavor, yet we believe that all the contributions herein offer new research questions, alternative research designs, and discerning solutions to the issues to which they call attention. May it serve as a prospect and source of discoveries that will further expand interdisciplinary inquiry into the nexus of geography, networks, and knowledge. 


\section{References}

Abbott, A. D. (2001). Time matters: On theory and method. Chicago: University of Chicago Press.

Adams, J., Faust, K., \& Lovasi, G. S. (2012). Capturing context: Integrating spatial and social network analyses. Social Networks, 34, 1-5. doi:10.1016/j.socnet.2011.10.007

Allen, T. J. (1977). Managing the flow of technology: Technology transfer and the dissemination of technological information within the $R \& D$ organization. Cambridge, MA: MIT Press.

Almeida, P., \& Kogut, B. (1999). Localization of knowledge and the mobility of engineers in regional networks. Management Science, 45, 905-917. doi:10.1287/mnsc.45.7.905

Balland, P.-A. (2012). Proximity and the evolution of collaboration networks: Evidence from research and development projects within the Global Navigation Satellite System (GNSS) industry. Regional Studies, 46, 741-756. doi:10.1080/00343404.2010.529121

Baron, R. M., \& Kenny, D. A. (1986). The moderator-mediator variable distinction in social psychological research: Conceptual, strategic, and statistical considerations. Journal of Personality and Social Psychology, 51, 1173-1182. doi:10.1037/0022-3514.51.6.1173

Bathelt, H. (2001). Regional competence and economic recovery: Divergent growth paths in Boston's high technology economy. Entrepreneurship \& Regional Development, 13, 287-314. doi:10.1080/08985620110067502

Bathelt, H., \& Glückler, J. (2005). Resources in economic geography: From substantive concepts towards a relational perspective. Environment and Planning A, 37, 1545-1563. doi:10.1068/ a37109

Bathelt, H., \& Glückler, J. (2011). The relational economy: Geographies of knowing and learning. Oxford: University Press. doi:10.1111/jors.12024_4

Bell, G. G., \& Zaheer, A. (2007). Geography, networks, and knowledge flow. Organization Science, 18, 955-972. doi:10.1287/orsc.1070.0308

Blau, P. M. (1964). Exchange and power in social life. New York: John Wiley \& Sons.

Borgatti, S. P., \& Cross, R. (2003). A relational view of information seeking and learning in social networks. Management Science, 49, 432-445. doi:10.1287/mnsc.49.4.432.14428

Borgatti, S. P., \& Halgin, D. S. (2011). On network theory. Organization Science, 22, 1168-1181. doi:10.1287/orsc.1100.0641

Brailly, J., Favre, G., Chatellet, J., \& Lazega, E. (2016a). Embeddedness as a multilevel problem: A case study in economic sociology. Social Networks, 44, 319-333. doi:10.1016/j. socnet.2015.03.005

Brailly, J., Favre, G., Chatellet, J., \& Lazega, E. (2016b). Market as a multilevel system. In E. Lazega \& T. A. B. Snijders (Eds.), Multilevel network analysis for the social sciences: Theory, methods and applications (pp. 245-271). Methodos Series: Vol. 12. London: Springer.

Brandes, U. (2016). Network positions. Methodological Innovations, 9, 1-19. doi: $10.1177 / 2059799116630650$

Breiger, R. L. (1974). The duality of persons and groups. Social Forces, 53, 181-190. doi:10.1093/ $\mathrm{sf} / 53.2 .181$

Breiger, R. L. (Ed.). (1990). Social mobility and social structure. Cambridge, UK: University Press.

Breiger, R. L. (2010). Dualities of culture and structure: Seeing through cultural holes. In J. Fuhse \& S. Mützel (Eds.), Relationale Soziologie: Zur kulturellen Wende der Netzwerkforschung (pp. 37-47). Wiesbaden: Verlag für Sozialwissenschaften.

Breschi, S., Lenzi, C., Lissoni, F., \& Vezzulli, A. (2010). The geography of knowledge spillovers: The role of inventors' mobility across firms and in space. In R. A. Boschma \& R. Martin (Eds.), The handbook of evolutionary economic geography (pp. 353-369). Cheltenham: Edward Elgar. doi: $10.4337 / 9781849806497.00025$

Breschi, S., \& Lissoni, F. (2009). Mobility of skilled workers and co-invention networks: An anatomy of localized knowledge flows. Journal of Economic Geography, 9, 439-468. doi:10.1093/ jeg/lbp008

Broekel, T., \& Boschma, R. (2012). Knowledge networks in the Dutch aviation industry: The proximity paradox. Journal of Economic Geography, 12, 409-433. doi:10.1093/jeg/lbr010 
Brown, J. S., \& Duguid, P. (1991). Organizational learning and communities-of-practice: Toward a unified view of working, learning, and innovating. Organization Science, 2, 40-57. doi:10.1287/orsc.2.1.40

Burt, R. S. (1992). Structural holes: The social structure of competition. Cambridge, MA: Harvard University Press.

Burt, R. S. (2004). Structural holes and good ideas. American Journal of Sociology, 110, 349-399. doi: $10.1086 / 421787$

Butts, C. T., Acton, R. M., Hipp, J. R., \& Nagle, N. N. (2012). Geographical variability and network structure. Social Networks, 34, 82-100. doi:10.1016/j.socnet.2011.08.003

Camagni, R. (1991). Local 'milieu', uncertainty and innovation networks: Towards a new dynamic theory of economic space. In R. Camagni (Ed.), Innovation networks: Spatial perspectives (pp. 121-144). London: Belhaven Press.

Cattani, G., \& Ferriani, S. (2008). A core/periphery perspective on individual creative performance: Social networks and cinematic achievements in the Hollywood film industry. Organization Science, 19, 824-844. doi:10.1287/orsc.1070.0350

Cook, G. A. S., Pandit, N. R., Beaverstock, J. V., Taylor, P. J., \& Pain, K. (2007). The role of location in knowledge creation and diffusion: Evidence of centripetal and centrifugal forces in the City of London financial services agglomeration. Environment and Planning A, 39, 13251345. doi:10.1068/a37380

Daraganova, G., Pattison, P., Koskinen, J., Mitchell, B., Bill, A., Watts, M., \& Baum, S. (2012). Networks and geography: Modelling community network structures as the outcome of both spatial and network processes. Social Networks, 34, 6-17. doi:10.1016/j.socnet.2010.12.001

Doreian, P., Batagelj, V., \& Ferligoj, A. (2005). Generalized blockmodeling. Cambridge, UK: University Press.

Doreian, P., \& Conti, N. (2012). Social context, spatial structure and social network structure. Social Networks, 34, 32-46. doi:10.1016/j.socnet.2010.09.002

Durkheim, E. (1951). Suicide: A study in sociology. New York: Free Press. (Original work published 1897)

Emirbayer, M., \& Goodwin, J. (1994). Network analysis, culture, and the problem of agency. American Journal of Sociology, 99, 1411-1454. Retrieved from http://www.jstor.org/ stable/2782580

Favre, G., Brailly, J., Chatellet, J., \& Lazega, E. (2016). Inter-organizational network influence on long-term and short-term inter-individual relationships: The case of a trade fair for TV programs distribution in sub-Saharan Africa. In E. Lazega \& T. A. B. Snijders (Eds.), Multilevel network analysis for the social sciences: Theory, methods and applications (pp. 295-314). Methodos Series: Vol. 12. London: Springer.

Gertler, M. S. (1995). "Being there": Proximity, organization, and culture in the development and adoption of advanced manufacturing technologies. Economic Geography, 71, 1-26. doi: $10.2307 / 144433$

Glaeser, E. L. (2005). Reinventing Boston: 1630-2003. Journal of Economic Geography, 5, 119153. doi: $10.1093 / \mathrm{jnlecg} / \mathrm{lbh} 058$

Glückler, J. (2005). Making embeddedness work: Social practice institutions in foreign consulting markets. Environment and Planning A, 37, 1727-1750. doi:10.1068/a3727

Glückler, J. (2006). A relational assessment of international market entry in management consulting. Journal of Economic Geography, 6, 369-393. doi:10.1093/jeg/lbi016

Glückler, J. (2007). Economic geography and the evolution of networks. Journal of Economic Geography, 7, 619-634. doi:10.1093/jeg/lbm023

Glückler, J. (2010). The evolution of a strategic alliance network: Exploring the case of stock photography. In R. Boschma \& R. Martin (Eds.), The handbook of evolutionary economic geography (pp. 298-315). Cheltenham: Edward Elgar. doi:10.4337/9781849806497.00023

Glückler, J. (2013). Knowledge, networks and space: Connectivity and the problem of non-interactive learning. Regional Studies, 47, 880-894. doi:10.1080/00343404.2013.779659

Glückler, J., \& Hammer, I. (2012). Multilaterale Kooperation und Netzwerkgüter [Multilateral cooperation and network goods]. In J. Glückler, W. Dehning, M. Janneck, \& T. Armbrüster 
(Eds.), Unternehmensnetzwerke: Architekturen, Strukturen und Strategien (pp. 139-162). Heidelberg: Springer Gabler. doi:10.1007/978-3-642-29531-7_8

Grabher, G. (2006). Trading routes, bypasses, and risky intersections: Mapping the travels of 'networks' between economic sociology and economic geography. Progress in Human Geography, 30, 163-189. doi:10.1191/0309132506ph600oa

Granovetter, M. (1985). Economic action and economic structure: The problem of embeddedness. American Journal of Sociology, 91, 481-510. doi:10.1086/228311

Greenberg, M. R., Carey, G. W., Zobler, L., \& Hordon, R. M. (1971). A geographical systems analysis of the water supply networks of the New York metropolitan region. The Geographical Review, 61, 339-354. doi:10.2307/213432

Gulati, R. (1995). Does familiarity breed trust? The implications of repeated ties for contractual choice in alliances. Academy of Management Journal, 38, 85-112. doi:10.2307/256729

Haggett, P., \& Chorley, R. J. (1969). Network analysis in geography. London: Edward Arnold.

Hansen, M. T., \& Løvås, B. (2004). How do multinational companies leverage technological competencies? Moving from single to interdependent explanations. Strategic Management Journal, 25, 801-821. doi:10.1002/smj.413

Jacobs, J. (1969). The economy of cities. New York: Random House.

Jaffe, A. B., Trajtenberg, M., \& Henderson, R. (1993). Geographic localization of knowledge spillovers as evidenced by patent citations. Quarterly Journal of Economics, 108, 577-598. doi: $10.2307 / 2118401$

Keeble, D., \& Nachum, L. (2002). Why do business service firms cluster? Small consultancies, clustering and decentralization in London and southern England. Transactions of the Institute of British Geographers, New Series, 27, 67-90. doi:10.1111/1475-5661.00042

Kilduff, M, \& Brass, D. J. (2010). Organizational social network research: Core ideas and key debates. The Academy of Management Annals, 4, 317-357. doi:10.1080/19416520.2010.494827

Kilduff, M., \& Tsai, W. (2003). Social networks and organizations. London: Sage.

Klepper, S. (2010). The origin and growth of industry clusters: The making of Silicon Valley and Detroit. Journal of Urban Economics, 67, 15-32. doi:10.1016/j.jue.2009.09.004

Knorr-Cetina, K. (1981). The manufacture of knowledge: An essay on the constructivist and contextual nature of science. Oxford: Pergamon Press.

Krackhardt, D., \& Stern, R. N. (1988). Informal networks and organizational crises: An experimental simulation. Social Psychology Quarterly, 51, 123-140. Retrieved from http://www. jstor.org/stable/2786835

Lawson, C., \& Lorenz, E. (1999). Collective learning, tacit knowledge and regional innovative capacity. Regional Studies, 33, 305-317. doi:10.1080/713693555

Lazega, E. (2016). Synchronization costs in the organizational society: Intermediary relational infrastructures in the dynamics of multilevel networks. In E. Lazega \& T. A. B. Snijders (Eds.), Multilevel network analysis for the social sciences: Theory, methods and applications (pp. 47-77). Methodos Series: Vol. 12. London: Springer.

Lazega, E., Bar-Hen, A., Barbillon, P., Donnet, S. (2016). Effects of competition on collective learning in advice networks. Social Networks, 47, 1-14. doi:10.1016/j.socnet.2016.04.001

Lazega, E., \& Pattison, P. E. (1999). Multiplexity, generalized exchange and cooperation in organizations: A case study. Social Networks, 21, 67-90. doi:10.1016/S0378-8733(99)00002-7

Lazega, E., \& Pattison, P. E. (2001). Social capital as social mechanisms and collective assets: The example of status auctions among colleagues. In N. Lin, K. Cook, \& R. S. Burt (Eds.), Social capital: Theory and research (pp. 185-208). New York: Aldine de Gruyter.

Lomi, A., \& Pallotti, F. (2012). Relational collaboration among spatial multipoint competitors. Social Networks, 34, 101-111. doi:10.1016/j.socnet.2010.10.005

Lorenzen, M., \& Mudambi, R. (2013). Clusters, connectivity and catch-up: Bollywood and Bangalore in the global economy. Journal of Economic Geography, 13, 501-534. doi:10.1093/ jeg/lbs017

Malmberg, A., \& Maskell, P. (2002). The elusive concept of localization economies: Towards a knowledge-based theory of spatial clustering. Environment and Planning A, 34, 429-449. doi:10.1068/a3457

Marsden, P. V., \& Lin, N. (Eds.). (1982). Social structure and network analysis. Beverley Hills: Sage. 
Maskell, P. (2001). Towards a knowledge-based theory of the geographical cluster. Industrial and Corporate Change, 10, 921-943. doi:10.1093/icc/10.4.921

Maskell, P., \& Malmberg, A. (1999). Localised learning and industrial competitiveness. Cambridge Journal of Economics, 23, 167-185. doi:10.1093/cje/23.2.167

Matthes, F. E. (1912). Topology, topography and topometry. Bulletin of the American Geographical Society, 44, 334-339. Retrieved from http://www.jstor.org/stable/199822

Meusburger, P. (2009). Milieus of creativity: The role of places, environments, and spatial contexts. In P. Meusburger, J. Funke, \& E. Wunder (Eds.), Milieus of creativity: An interdisciplinary approach to spatiality of creativity (pp. 97-153). Knowledge and Space: Vol. 2. Dordrecht: Springer. doi:10.1007/978-1-4020-9877-2_7

Mitchell, J. C. (1969). The concept and use of social networks. In J. C. Mitchell (Ed.), Social networks in urban situations: Analyses of personal relationships in central African towns (pp. 1-50). Manchester: Manchester University Press.

Mizruchi, M. S. (1994). Social network analysis: Recent achievements and current controversies. Acta Sociologica, 37, 329-343. doi:10.1177/000169939403700403

Obstfeld, D. (2005). Social networks, the tertius iungens orientation, and involvement in innovation. Administrative Science Quarterly, 50, 100-130. doi:10.2189/asqu.2005.50.1.100

Owen-Smith, J., \& Powell, W. W. (2004). Knowledge networks as channels and conduits: The effects of spillovers in the Boston biotechnology community. Organization Science, 15, 5-21. doi:10.1287/orsc. 1030.0054

Piña-Stranger, A., \& Lazega, E. (2010). Inter-organisational collective learning: The case of biotechnology in France. European Journal of International Management, 4, 602-620. doi:10.1504/EJIM.2010.035591

Powell, W. W., Koput, K. W., \& Smith-Doerr, L. (1996). Interorganizational collaboration and the locus of innovation: Networks of learning in biotechnology. Administrative Science Quarterly, 41, 116-145. doi:10.2307/2393988

Powell, W. W., White, D. R., Koput, K. W., \& Owen-Smith, J. (2005). Network dynamics and field evolution: The growth of interorganizational collaboration in the life sciences. American Journal of Sociology, 110, 1132-1205. doi:10.1086/421508

Preciado, P., Snijders, T. A. B., Burk, W. J., Stattin, H., \& Kerr, M. (2012). Does proximity matter? Distance dependence of adolescent friendships. Social Networks, 34, 18-31. doi:10.1016/j. socnet.2011.01.002

Romer, P. M. (1990). Endogenous technological change. Journal of Political Economy, 98, 71-102. Retrieved from http://www.jstor.org/stable/2937632

Rosenkopf, L., \& Almeida, P. (2003). Overcoming local search through alliances and mobility. Management Science, 49, 751-766. doi:10.1287/mnsc.49.6.751.16026

Sagers, M. J., \& Green, M. B. (1982). Spatial efficiency in Soviet electrical transmission. Geographical Review, 72, 291-303. doi:10.2307/214528

Sailer, K., \& McCulloh, I. (2012). Social networks and spatial configuration-How office layouts drive social interaction. Social Networks, 34, 47-58. doi:10.1016/j.socnet.2011.05.005

Saxenian, A. L. (1994). Regional advantage: Culture and competition in Silicon Valley and Route 128. Cambridge, MA: Harvard University Press.

Schumpeter, J. A. (1911). Theorie der wirtschaftlichen Entwicklung [A theory of economic development]. Berlin: Duncker und Humblot.

Snijders, T. A. B. (2005). Models for longitudinal network data. In P. J. Carrington, J. Scott, \& S. Wasserman (Eds.), Models and methods in social network analysis (pp. 215-247). Structural Analysis in the Social Sciences: Vol. 28. Cambridge, UK: Cambridge University Press.

Snijders, T. A. B., \& Steglich, C. E. G. (in press-a). Actor-based models for analyzing network dynamics. Structural Analysis in the Social Sciences series. Cambridge, UK: Cambridge University Press.

Snijders, T. A. B., \& Steglich, C. E. G. (Eds.). (in press-b). Social network dynamics by examples. Structural Analysis in the Social Sciences series. Cambridge, UK: Cambridge University Press.

Song, J., Almeida, P., \& Wu, G. (2003). Learning-by-hiring: When is mobility more likely to facilitate interfirm knowledge transfer? Management Science, 49, 351-365. doi:10.1287/ mnsc.49.4.351.14429 
Storper, M. (1997). The regional world: Territorial development in a global economy. New York: Guilford Press.

Takhteyev, Y., Gruzd, A., \& Wellman, B. (2012). Geography of Twitter networks. Social Networks, 34, 73-81. doi:10.1016/j.socnet.2011.05.006

Thompson, P., \& Fox-Kean, M. (2005). Patent citations and the geography of knowledge spillovers: A reassessment? American Economic Review, 95(1), 450-460. doi: $10.1257 / 0002828053828509$

Tödtling, F. (1994). Regional networks of high-technology firms: The case of the Greater Boston Region. Technovation, 14, 323-343. doi:10.1016/0166-4972(94)90075-2

Uzzi, B., \& Lancaster, R. (2003). Relational embeddedness and learning: The case of bank loan managers and their clients. Management Science, 49, 383-399. doi:10.1287/ mnsc.49.4.383.14427

Vedres, B., \& Stark, D. (2010). Structural folds: Generative disruption in overlapping groups. American Journal of Sociology, 115, 1150-1190. doi:10.1086/649497

Verdery, A. M., Entwisle, B., Faust, K., \& Rindfuss, R. R. (2012). Social and spatial networks: Kinship distance and dwelling unit proximity in rural Thailand. Social Networks, 34, 112-127. doi:10.1016/j.socnet.2011.04.003

Viry, G. (2012). Residential mobility and the spatial dispersion of personal networks: Effects on social support. Social Networks, 34, 59-72. doi:10.1016/j.socnet.2011.07.003

von Hippel, E. (1994). "Sticky information" and the locus of problem solving: Implications for innovation. Management Science, 40, 429-439. doi:10.1287/mnsc.40.4.429

Wasserman, S., \& Faust, K. (1994). Social network analysis: Methods and applications. Cambridge, UK: Cambridge University Press.

Wellman, B., \& Berkowitz, S. D. (1988). Social structures: A network approach. Structural Analysis in the Social Sciences: Vol. 2. Cambridge, UK: Cambridge University Press.

Wenger, E. C. (1998). Communities of practice: Learning, meaning, and identity. Cambridge, UK: Cambridge University Press.

White, H. C. (2008). Identity and control: How social formations emerge. Princeton: Princeton University Press.

Whittington, K. B., Owen-Smith, J., \& Powell, W. W. (2009). Networks, propinquity, and innovation in knowledge-intensive industries. Administrative Science Quarterly, 54, 90-122. doi:10.2189/asqu.2009.54.1.90

Zaheer, A., Gözübüyük, R., \& Milanov, H. (2010). It's the connections: The network perspective in interorganizational research. Academy of Management Perspectives, 24(1), 62-77. doi:10.5465/AMP.2010.50304417

Zipf, G. K. (1949). Human behavior and the principle of least effort. Cambridge, MA: AddisonWesley Press.

Open Access This chapter is distributed under the terms of the Creative Commons Attribution 4.0 International License (http://creativecommons.org/licenses/by/4.0/), which permits use, duplication, adaptation, distribution and reproduction in any medium or format, as long as you give appropriate credit to the original author(s) and the source, provide a link to the Creative Commons license and indicate if changes were made.

The images or other third party material in this chapter are included in the work's Creative Commons license, unless indicated otherwise in the credit line; if such material is not included in the work's Creative Commons license and the respective action is not permitted by statutory regulation, users will need to obtain permission from the license holder to duplicate, adapt or reproduce the material.

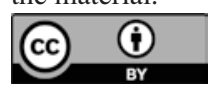

